\title{
Autosomal recessive Charcot-Marie-Tooth disease with hoarseness
}

INSERM

\section{Source}

INSERM. (1999). Orphanet: an online rare disease and orphan drug data base. Autosomal recessive Charcot-Marie-Tooth disease with hoarseness. ORPHA:101097

Autosomal recessive Charcot-Marie-T ooth disease with hoarseness (ARCMT2K or CMT 4C4) is a severe early-onset form of axonal CMT peripheral sensorimotor polyneuropathy. 